\title{
Migration and genetic regulation of the pre- reproductive period in the Cotton-bollworm moth, Helicoverpa armigera
}

\author{
JOHN COLVIN* \& A. GAVIN GATEHOUSE† \\ *Natural Resources Institute, Central Avenue, Chatham Maritime, Chatham, Kent ME4 4TB and TSchool of Biological \\ Sciences, University College of North Wales, Bangor, Gwynedd LL57 2UW, U.K.
}

\begin{abstract}
The pre-reproductive period (PRP) is of interest in the study of noctuid migration because it approximates to the number of nights in which migratory flight can occur. This study examined the pre-calling period $(\mathrm{PCP}=$ female $\mathrm{PRP})$ distribution of Indian, Malawian and Chinese Helicoverpa armigera strains and found them to be significantly different. A PCP sib-analysis experiment was conducted both on the Malawian and on the Chinese strains. In both sib-analysis experiments, the sire component of variance was significant and greater than that of the dam component. As females are the heterogametic sex in Lepidoptera, this suggests that some genes influencing the PCP are $\mathrm{X}$-linked. Male moths were also shown to have PRPs, the distribution of which was not significantly different from that of their female siblings. A selection experiment, based on the PCP only, produced two divergent lines of early- and late-maturing females after only two generations of selection. After three generations of selection, the male PRP distributions in the two lines were examined and were found to differ significantly. The divergence occurred in the same direction as for females, suggesting that the same set of genes regulates the PRP in both sexes. The results of this study are considered in relation to the evolution of migration in $H$. armigera.
\end{abstract}

Keywords: Helicoverpa (Heliothis) armigera, migration, pre-reproductive period, X-linkage.

\section{Introduction}

The two components of noctuid migratory potential that are readily measurable in the laboratory are the pre-reproductive period (PRP) and flight activity. The PRP is of interest because migratory flight by many insect species occurs in immature individuals (Johnson, 1969) and therefore the PRP approximates to the number of nights in which migratory behaviour may occur. The interaction between the PRP and flight activity, as well as the inheritance of tethered-flight potential in the cotton-bollworm moth, Helicoverpa (Heliothis) armigera, have been described (Colvin \& Gatehouse, 1993).

A genetic component to the migratory behaviour of many insect species has been recognized for some time (review by Gatehouse, 1989). There have, however, been relatively few studies on the genetic regulation of the PRP. Derr (1980), working on the cotton stainer bug, Dysdercus bimaculatus, obtained a significant

${ }^{*}$ Correspondence. estimate of heritability for the PRP $(0.3-0.4)$ and suggested that the genes for this trait were carried on the autosomes. Hegmann \& Dingle (1982) carried out sib-analysis experiments on the milkweed bug, Oncopeltus fasciatus, examining the inheritance of several different life-history traits. Insects reared under a long photoperiod showed an estimate of heritability for the PRP approximately one-third of that produced under short photoperiodic conditions. A further discovery was that the PRP failed to show any genetic correlations with the other traits measured. It was suggested that there would be a 'cost of correlation' if this were not so, as the variation in the PRP would become 'tied up' by directional selection on the other traits.

Han \& Gatehouse (1991) used the pre-calling period (PCP) of Oriental armyworm moths, Mythimna separata, as a measure of the female PRP. Because the PCP is sex-limited, several different approaches were used to examine its mode of inheritance, their results revealing that loci both on the $\mathrm{X}$-chromosome and the autosomes exerted an influence on the PCP. Wilson \& Gatehouse (1992) and Hill \& Gatehouse (1992) have 
also recently demonstrated an X-linked influence on the PRP of the African armyworm moth, Spodoptera exempta and the silver-Y moth, Autographa gamma, respectively.

In this paper, we describe the importance of heredity in the regulation of the PRP in both sexes of adult $H$. armigera.

\section{Materials and methods}

\section{Experimental room and larval rearing}

Experiments were conducted in a controlled environment (LD 14:10 h, 26 $\pm 1^{\circ} \mathrm{C} ; 65 \pm 5$ per cent r.h.). Background illumination was provided during the scotophase by a $60 \mathrm{~W}$ red light bulb placed behind a red filter (600-1200 nm wavelength).

Larvae were reared individually in separate $30 \mathrm{ml}$ plastic pots and fed on germinated chick-pea seeds, Cicer arietinum.

\section{Insects and PRP assessment}

The $H$. armigera strains used to compare the PCP distributions of females from different geographical regions were $F_{1}, F_{1}$ and $F_{6}$ laboratory generation Indian, Malawian and Chinese moths, respectively. The Chinese PCP data were obtained from the sibanalysis experiment. The two PCP sib-analysis experiments used $F_{1}$ and $F_{5}$ moths as the parental generations in the Malawian and Chinese strains, respectively. Experiment 3, comparing the PRP distributions of males and females, used the $F_{1}$ laboratory generation of 27 families of Indian moths. The parental generation in the selection experiment were $F_{1}$ Malawian insects.

The age of each moth was measured in nights after eclosion, the night of eclosion being designated night 0 . On night 0 , moths were placed in $300 \mathrm{ml}$ clear-plastic containers and allowed to feed ad libitum on $10 \%$ $(\mathrm{w} / \mathrm{v})$ sugar solution which was always available thereafter.

Only reproductively mature female moths 'call' (release pheromone), a behaviour recognized by the presence of the female's extruded ovipositor (Kou \& Chow, 1987). Calling and mating behaviour usually takes place in the second half of the scotophase (Kou \& Chow, 1987; Colvin, 1990) and so the PCP of each female (equivalent to the female PRP) was determined by observing her at $10 \mathrm{~min}$ intervals, during the last $3 \mathrm{~h}$ of every night, until she called. The age at which a female started to call was recorded as her PCP.

The PRPs of the males were determined by releasing them each night, one at a time, into a netting cage containing three calling females. If the male was initially inactive, he was lifted out of his container and placed on the cage netting. Males were given a maximum of $5 \mathrm{~min}$ in which to attempt to mate, although when mature $30 \mathrm{~s}$ was usually sufficient.

Male mating behaviour was distinctive, consisting of brush extension and swiping movements of the abdomen towards one of the calling females. Those males that did not attempt to mate during the 5-min period were classified as immature and were tested again the following night. The age at which a male first attempted to mate was recorded as his PRP. Almost all individuals of both sexes $(\sim 98$ per cent $)$ exhibited reproductive behaviour before death.

\section{Female PRP distributions}

The aim of this experiment was to determine whether differences existed in the PRP distributions of females originating from widely separated geographical regions. Female PRP distributions were obtained from the daughters of 10 Malawian-moth pairs, 14 Indianmoth pairs and 38 Chinese-moth pairs. Pupae from India, Malawi and China arrived on different dates and therefore observations on the strains were not conducted simultaneously.

\section{Sib-analysis experiments}

The differences in the PCP distributions under similar environmental conditions (Fig. 1) suggested a significant genetic influence on the PCP (see Falconer, 1963). The aim of these experiments, therefore, was both to confirm this and to investigate the mode of inheritance of the PCP. A sib-analysis experimental design was chosen because calling behaviour is sex-limited and at this point it was not known whether males showed variation in their PRPs.

Owing to the small number of healthy moths available for the Malawian PCP sib-analysis, only four parental male moths (sires) were each mated to two different females (dams). The sib-analysis was repeated, therefore, using a Chinese strain of moths where 14 sires were mated randomly either to two or to three different females.

In both experiments, the female offspring from the progeny groups were arranged randomly on the bench with the family (offspring of a single pair of moths) identification labels positioned face-down in the containers. Thus, each female's family group remained unknown until she called.

\section{Male and female PRP distributions}

This experiment was designed to discover whether male $H$. armigera also show variation in the duration of their PRPs, and whether this variation is similar to that 

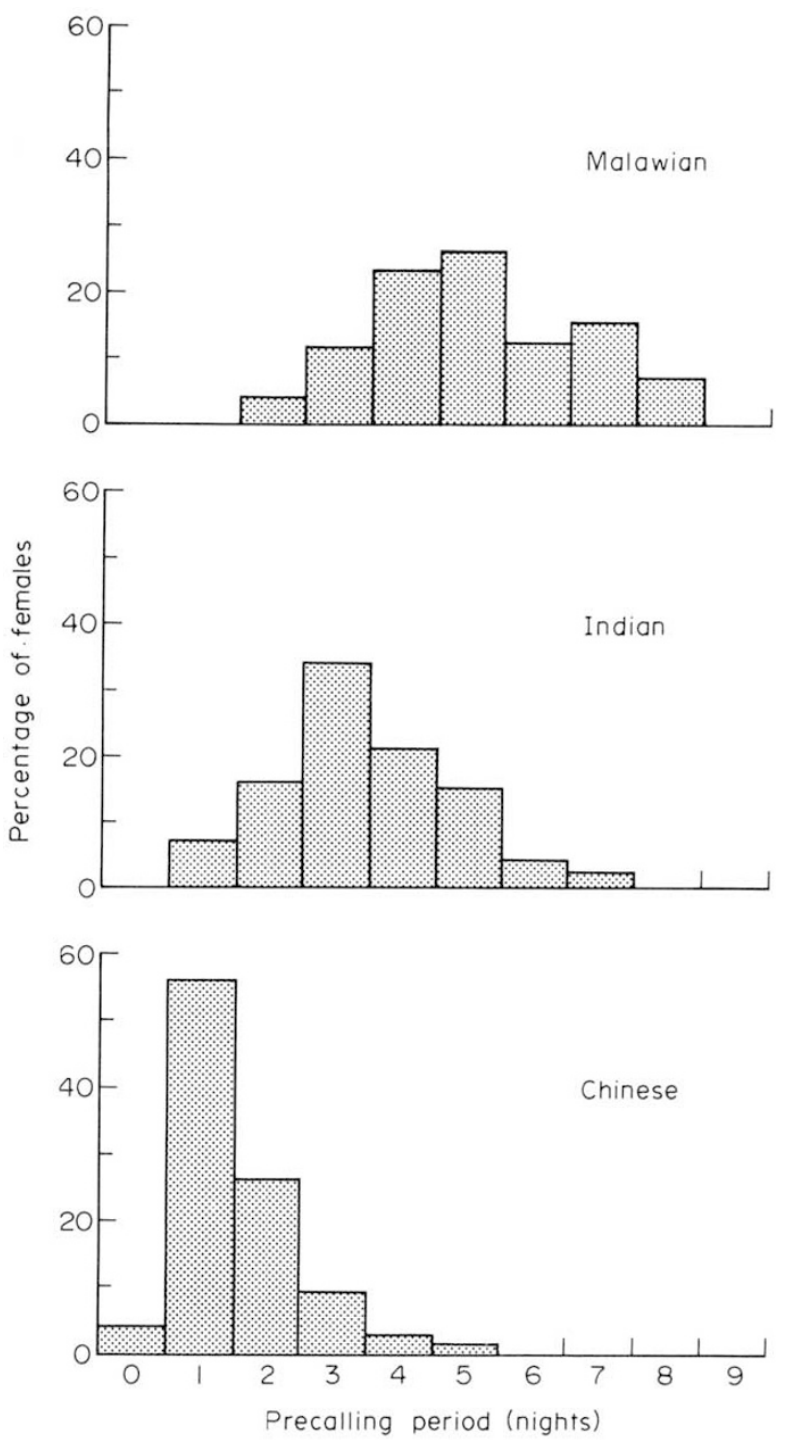

Fig. 1 Pre-calling period distributions of Malawian, Indian and Chinese H. armigera $(P<0.001$, Kruskal-Wallis $)$. Sample sizes were Malawian $=50$, Indian $=56$, Chinese $=$ 460.

shown by females. The offspring of 27 field-collected moth pairs were used to obtain PRP distributions for both sexes (see above for PRP assessment).

\section{Selection on the PRP}

The previous experiment revealed that males exhibit variation in their PRP and that when the offspring of a large number of families was examined, the male PRP distribution was not significantly different from that of females. This experiment, therefore, aimed to discover whether the genes controlling the PCP also influence the male PRP.
Selection was conducted solely on the basis of the PCP. To establish early- and late-calling lines, Malawian females were chosen that called on nights 1-3 and 6-10, respectively. In both lines, females were mated randomly to their male siblings and, in each generation, fertile eggs were collected from at least 10 females to avoid the possibility of disease wiping out a line.

In the $\mathrm{F}_{3}$ generation, the PRPs of the male siblings in the two selected lines were assessed. To remove operator bias, males of both lines were assigned arbitrary numbers during maturity assessment so that each male's family history was unknown until it was seen to respond to a calling female.

Results of this experiment were analysed using the Mann-Whitney test and not by regression of cumulative response on cumulative selection differential. This was because data were available for only three generations of selection.

\section{Results}

\section{PCP distributions}

The PCP distributions of the three geographic strains were significantly different $(P<0.001$, KruskalWallis), Indian moths calling $\sim$ two nights earlier than Malawian moths and Chinese moths calling $\sim$ two nights earlier than Indian moths (Fig. 1). These differences suggest a genetic influence on the PCP.

\section{PCP sib-analysis experiments}

Data for the Malawian sib-analysis were normal $(P<0.05$, normal probability plot $)$ and so were analysed using the GENSTAT program for a hierarchical analysis of variance. The small number of d.f. (3), however, results in unreliable heritability estimates (sirecomponent: $h^{2}=1.59, \quad P<0.001$; dam-component: $\left.h^{2}=-0.07, \mathrm{~ns}\right)$.

The Chinese PCP data best fit a Poisson distribution and so a hierarchical analysis of variance was conducted with the GLIM statistical package, using the Poisson-error option. The larger number of d.f. $(13)$ in this experiment improves our confidence in the power of the statistical analysis and the heritability estimates (sire-component: $h^{2}=0.58, P<0.01$; dam-component: $h^{2}=0.12$, ns). To calculate S.E., the analysis was repeated with the assumption of underlying normality. This gave very similar results (sire-component: $h^{2}=0.54 \pm$ S.E. $\quad 0.25, \quad P<0.01 ; \quad$ dam-component: $h^{2}=0.16 \pm 0.13$, ns) and indicated that the sire and dam heritability estimates are not significantly different. 
Table 1 Pre-calling period sib-analysis experiments on Malawian and Chinese H. armigera. The small number of d.f. for the Malawian experiment makes these $h^{2}$ values unreliable. In both experiments, the between-sire component is significant and much greater than the between-dam component suggesting X-linkage of the PCP genes

\begin{tabular}{|c|c|c|c|c|c|c|c|}
\hline $\begin{array}{l}\text { Source of } \\
\text { variance }\end{array}$ & d.f. & $\begin{array}{l}\text { Mean } \\
\text { square }\end{array}$ & $\begin{array}{l}\text { Mean } \\
\text { deviance }\end{array}$ & $F$ & $P$ & $\begin{array}{l}\text { Component of } \\
\text { variance }\end{array}$ & $\begin{array}{l}\text { Estimates of } \\
\text { heritability }\end{array}$ \\
\hline \multicolumn{8}{|l|}{ Malawian } \\
\hline Between sires & 3 & 53.64 & & 31.60 & $* * *$ & 1.780 & $\begin{array}{l}\text { Sire-component: } \\
h^{2}=1.59\end{array}$ \\
\hline $\begin{array}{l}\text { Between dams, } \\
\text { within sires }\end{array}$ & 4 & 1.70 & & 0.62 & ns & -0.073 & $\begin{array}{l}\text { Dam-component: } \\
h^{2}=-0.07\end{array}$ \\
\hline Within progenies & 119 & 2.75 & & & & 2.753 & \\
\hline Total & 126 & & & & & 4.460 & \\
\hline \multicolumn{8}{|l|}{ Chinese } \\
\hline Between sires & 13 & & 3.259 & 5.01 & $* *$ & 0.080 & $\begin{array}{l}\text { Sire-component: } \\
h^{2}=0.58\end{array}$ \\
\hline $\begin{array}{l}\text { Between dams, } \\
\text { within sires }\end{array}$ & 22 & & 0.650 & 1.44 & ns & 0.017 & $\begin{array}{l}\text { Dam-component: } \\
h^{2}=0.12\end{array}$ \\
\hline Within progenies & 424 & & 0.452 & & & 0.452 & \\
\hline Total & 459 & & & & & 0.549 & \\
\hline
\end{tabular}

$*^{*} P<0.01$

ns $P>0.05$

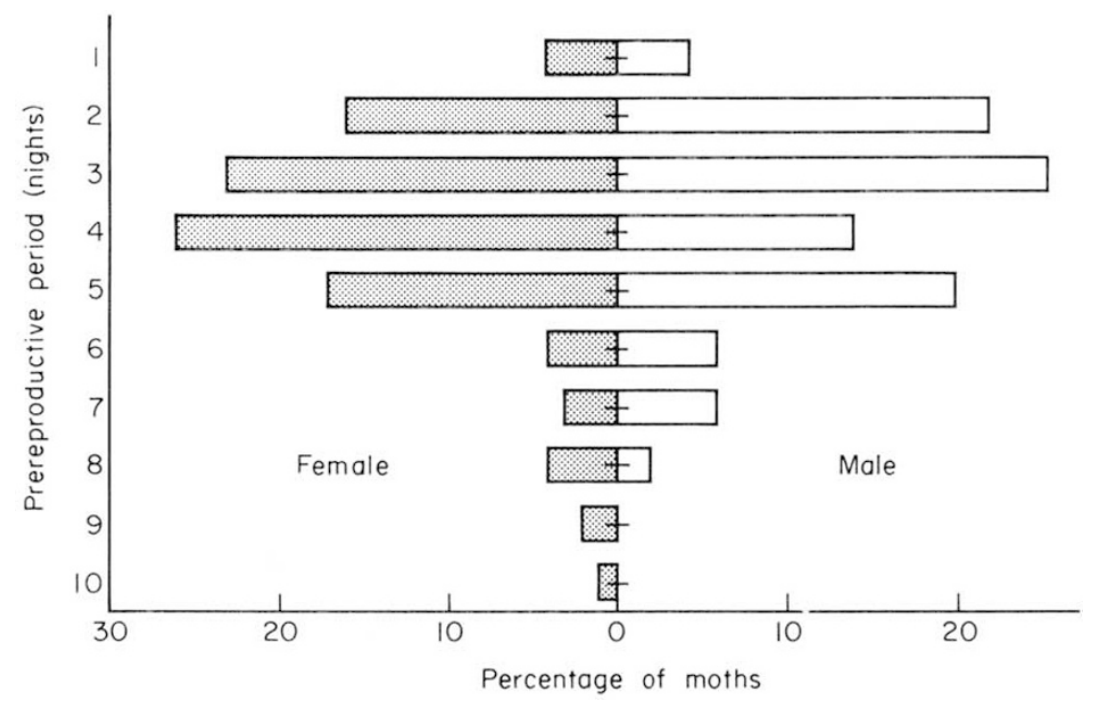

Fig. 2 Pre-reproductive period distributions of male and female Indian $H$. armigera $(P=0.3, t$-test $)$. Sample sizes were females $=104$, males $=66$.
A finding common to both these experiments is that sires contribute a significant component of variance to the daughters, whereas dams do not. As females are the heterogametic sex in Lepidoptera, these results suggest $\mathrm{X}$-linkage of the genes regulating the PCP.

\section{Male PRP distribution}

This experiment reveals for the first time that males exhibit variation in their PRPs and that the distributions for the sexes are similar $(P=0.3, t$-test of the difference between the means) (Fig. 2). The PCPs were significantly longer in this experiment than in the Indian moths in the first experiment $(P=0.032, t$-test $)$.

\section{PRP gene expression in both sexes}

The results of the selection experiment may be summarized as follows. After a single generation of selection, the early line (e) and late line (1) had the same median PCP (night 4), and had not diverged significantly. By the $F_{2}$ generation, however, a significant 
divergence had occurred between the two lines $\left(P<0.05\right.$, median $_{1}=4.5$, median $_{\mathrm{e}}=2$, Mann-Whitney $)$, which was maintained in the $\mathrm{F}_{3}$ generation $(P<0.05$, median $_{\mathrm{e}}=3$, median $\left._{1}=5\right)$. Between 30 and 87 female moths were tested in each generation, for each selected line.

The male PRP distributions in the two lines were assessed in the $\mathrm{F}_{3}$ generation and were found to have diverged significantly $\left(P<0.01, \operatorname{median}_{\mathrm{e}}=3\right.$, $\operatorname{median}_{l}=6, N_{\mathrm{e}}=37, N_{1}=39$ ), and in the same direction as for females.

These results suggest that the same group of $\mathrm{X}$-linked loci control the rate of reproductive maturation in both sexes of $H$. armigera.

\section{Discussion}

The PCP distributions of the three $H$. armigera strains (Fig. 1) provide the first evidence of a genetic influence on this trait (see Falconer, 1963, 1989), in a species previously considered to be a facultative migrant (Hackett, 1980; Fitt, 1989).

Results of both sib-analysis experiments support this view and suggest that the PCP genes are situated on the $\mathrm{X}$-chromosome. This result is similar to that found in other noctuid species (Han \& Gatehouse, 1991; Hill \& Gatehouse, 1992; Wilson \& Gatehouse, 1992).

The male PRP experiment revealed that males also have variation in their PRPs and that their PRP distribution is similar to that of their female siblings.

The selection experiment suggests that the same group of genes regulates the rate of reproductive maturation in both sexes. Female PCP genes and male PRP genes, therefore, may be considered more aptly as simply PRP genes.

The discovery of a genetic influence on the PRP is interesting, especially as $H$. armigera is known to be a facultative migrant, sensitive to environmental cues that signal a deterioration in habitat suitability (see also Colvin \& Gatehouse, 1993). It also highlights a potential problem associated with keeping laboratory cultures over many generations. In most cultures, it is probable that late-maturing moths are at a selective disadvantage; they are probably the last to mate and so, because of the high fecundity of females, will probably contribute fewer individuals to the next generation. In addition, the general 'wear and tear' moths experience in the laboratory will reduce the mating success of latematuring individuals. Thus, unless active steps are taken to retain late-maturing genes within a laboratory population, their frequency will decline rapidly. This would explain the short PCPs of the Chinese strain as they had been maintained in the laboratory for six generations prior to testing.
Many other traits, such as oviposition preference and pheromone recognition, etc. probably have a genetic basis and may be similarly affected by laboratory rearing. It is evident, therefore, that usually only the first one or two generations of an insect culture should be used in behavioural studies.

The results of this work raise several further questions: why does variation in the PRP exist and what causes it? Why should the PRP genes be located on the $\mathrm{X}$-chromosome and does this have any significance for migration?

Southwood (1977) argued that the ability to migrate (and/or diapause) would be selected for in species occupying ephemeral habitats. He suggested that, because of the unpredictable nature of these environments in space and time, maximum reproductive success would often be achieved by partitioning offspring between various strategies. Variation in migratory potential (as measured by the PRP), therefore, may be considered as the product of selection for coping with spatial unpredictability of resources.

As mentioned previously, X-linkage of the PRP has been demonstrated in three other noctuid species besides H. armigera. Han \& Gatehouse (1991) proposed that X-linkage of the PRP may have been an essential pre-adaptation for the stability of migratory incursions into temperate latitudes. Of importance to this theory is the greater genetic load that might be incurred by autosomal regulation of the PCP. This idea is perhaps of less significance in relation to migration by $H$. armigera, which only rarely reaches latitudes as far north as the British Isles (Pedgley, 1985).

Charlesworth et al. (1987) noted that, in general, traits intimately associated with fitness tend to be $\mathrm{X}$-linked and we suggest that the PRP of noctuids is another example of this. In addition, Charlesworth et al. (1987) showed that in comparison with autosomally inherited traits, X-linked ones, when certain conditions are fulfilled, can have a decreased rate of fixation in response to directional selection. X-linkage of the PRP, therefore, may help maintain important variation in migratory potential.

To conclude, if Southwood's (1977) hypothesis is accepted, the data presented in this paper suggest that differences exist between Malawi and central India in the spatial and/or temporal distribution of resources important to $H$. armigera. Migratory activity per se, however, is probably equally important in both regions.

\section{Acknowledgements}

We are grateful to Dr A. King and Mr Mchowa for providing the insects used in this study. The work formed part of the submission by J.C. for the degree of Ph.D. of 
the University of Wales. We thank Dr C. Gay and Dr S. Young for statistical advice. J.C. was financed by a SERC/CASE award with the National Resources Institute. MAFF licence number PHS 66A/64(100).

\section{References}

CHARlesworTh, B., COYNE, J. A. AND BARTON, N. H. 1987. The relative rates of evolution of sex chromosomes and autosomes. Am. Nat., 130, 113-146.

COLvin, J. 1990. Laboratory studies on the regulation of migration in the cotton-bollworm moth, Heliothis armigera ( $\mathrm{Hb}$. (Lepidoptera: Noctuidae). Ph.D. Thesis, University College of North Wales, Bangor.

COLVIN, J. AND GATEHOUSE, A. G. 1993. The reproduction-flight syndrome and the inheritance of tethered-flight activity in the Cotton-bollworm moth, Heliothis armigera. Physiol. Entomol. 18 (in press).

DERR, J. A. 1980. The nature of variation in life-history characters of Dysdercus bimaculatus (Heteroptera: Pyrrhocoridae), a colonizing species. Evolution, 34, 548-557.

FALCONER, D. S. 1963. Quantitative inheritance. In: W. J. Burdette (ed.) Methodology in Mammalian Genetics, Holden-Day, San Francisco, CA, pp. 193-216.

FALCONER, D. S. 1989. Introduction to Quantitative Genetics, 3rd edn. Longman, London and New York.

FITT, G. P. 1989. The Ecology of Heliothis species in relation to Agroecosystems. Ann. Rev. Entomol., 34, 17-52.
GATEHouse, A. G. 1989. Genes, environment and insect flight. In: Goldsworthy, G. J. and Wheeler, C. (eds) Insect Flight, CRC Press Inc., Boca Raton, FL, pp. 116-138.

HACKETT, D. S. 1980. Studies on the biology of Helicoverpa armigera armigera $(\mathrm{Hb})$ in the Sudan Gezira. Ph.D. Thesis, Univer sity College of North Wales, Bangor.

HAN, E. AND GATEHOUSE, A. G. 1991. Genetics of pre-calling period in the oriental armyworm, Mythimna separata (Walker) (Lepidoptea: Noctuidae), and implications for migration. Evolution, 45, 1502-1510.

HeGmanN, J. P. AND DINGLE, H. 1982. Phenotypic and genetic covariance structure in milkweed bug life-history traits. In: Dingle, H. and Hegmann, J.P. (eds) Evolution and Genetics of Life Histories, Springer, New York, pp. 177-184.

HILL, J. K. AND GATEHOUSE, A. G. 1992. Genetic control of the prereproductive period in the Silver-Y moth, Autographa gamma (L.) (Lepidoptera: Noctuidae). Heredity, 69, 458-464.

JoHnson, C. G. 1969. Migration and Dispersal of Insects by Flight. Methuen, London.

KOU, R. AND CHOW, Y. s. 1987. Calling behaviour of the cotton bollworm Heliothis armigera (Lepidoptera: Noctuidae). Ann. Entomol. Soc. Am., 80, 490-493.

PEDGELEY, D. E. 1985. Windborne migration of Heliothis armigera (Hb.) (Lepidoptera: Noctuidae) to the British Isles. Entomol. Gaz., 11, 15-20.

SOUTHwood, T. R. E. 1977. Habitat, the templet for ecological strategies? J. Anim. Ecol., 46, 337-365.

WILSON, K. AND GATEHOUSE, A. G. 1992. Migration and genetics of prereproductive period in the African armyworm moth, Spodoptera exempta. Heredity, 69, 255-262. 